\title{
Application of Early Enteral Nutrition in Critically Ill Children
}

\author{
Musheng Li*, Lini Chen \\ Pediatric Intensive Care Unit, Guangzhou Women and Children's Medical Center, Guangzhou Medical University, Guangzhou, \\ China \\ Email: *sukeric@126.com
}

How to cite this paper: Li, M.S. and Chen, L.N. (2021) Application of Early Enteral Nutrition in Critically Ill Children. Open Journal of Pediatrics, 11, 543-550.

https://doi.org/10.4236/ojped.2021.114050

Received: September 9, 2021

Accepted: September 27, 2021

Published: September 30, 2021

Copyright $\odot 2021$ by author(s) and Scientific Research Publishing Inc. This work is licensed under the Creative Commons Attribution International License (CC BY 4.0).

http://creativecommons.org/licenses/by/4.0/

\begin{abstract}
Objective: The objective is to investigate the incidence of moderate and severe malnutrition in children in intensive care units, and to analyze the safety and clinical efficacy of early enteral nutrition therapy in critically ill children. Methods: A total of 80 children hospitalized in the pediatric care unit meeting the inclusion criteria were selected and general data were collected, including 48 in the early enteral nutrition (EEN) group and 32 in the late EN group. The two groups were compared in the incidence of moderate to severe malnutrition, feeding tolerance, length of stay in ICU, total length of stay, changes in blood routine and biochemical indicators. Results: After 1 week in ICU, the feeding tolerance of the treatment group was better than that of the control group $(\mathrm{P}<0.05)$. The average length of stay in ICU and total length of stay in the treatment group were shorter than those in the control group $(\mathrm{P}<$ 0.05). After 1 week of comprehensive treatment (anti-infection and EEN), the total number of WBC, absolute value of neutrophil and C-reactive protein in peripheral blood of the treatment group were decreased $(\mathrm{P}<0.01)$, which was significantly lower than that of the control group with bacterial infection $(\mathrm{P}<$ 0.01). After 1 week of treatment in ICU, serum prealbumin in treatment group was significantly higher than that in control group $(P<0.05)$, but serum albumin was not significantly higher $(\mathrm{P}>0.05)$. The rate of moderate to severe malnutrition at discharge was lower in the treatment group than at admission to the ICU (17 cases vs. 20 cases, $35.4 \%$ vs. $41.7 \%$ ), but higher in the control group (19 cases vs. 16 cases, $59.4 \%$ vs. $50.0 \%$ ). Conclusion: Malnutrition is prevalent in children treated in pediatric intensive care units. Early enteral nutrition therapy for critically ill children is safe and effective, that can significantly improve the nutritional status of critically ill children, reduce inflammatory response, and shorten the hospital stay.
\end{abstract}

\section{Keywords}

Early Enteral Nutrition, Childhood, Critical Care, Intensive Care Unit 


\section{Introduction}

Pediatric Intensive Care Unit (PICU) has a high incidence of malnutrition. Hulst [1] reported that about $24 \%$ of children with PICU had acute or chronic malnutrition. Malnutrition can not only prolong the course of disease, but also easily lead to the development of multiple organ failure [2]. It is currently believed that early enteral nutrition (EEN) can reduce stress response and catabolism degree of critically ill patients, shorten the high metabolic period, reduce the release of inflammatory mediators, reduce the occurrence of infection, promote anabolism and body recovery, maintain and improve intestinal and body immune function.

\section{Patients and Methods}

\subsection{Patients}

A retrospective analysis of critically ill children hospitalized in the intensive care unit of our hospital from November 01, 2017 to December 31, 2020 was performed, including 80 children who met the inclusion and exclusion criteria of the study.

\subsection{Inclusion and Exclusion Criteria}

\subsubsection{Inclusion Criteria}

1) Age $\leq 6$ years, no gender limitation; 2) Hospitalization duration $\geq 1$ week without death; 3) Children were admitted to intensive care unit after surgery for congenital heart disease, abdominal mass and intestinal disease, or were admitted to intensive care unit for respiratory and circulatory failure requiring advanced life support; 4) No organic diseases such as digestive tract obstruction and perforation occurred after admission to ICU.

\subsubsection{Exclusion Criteria}

1) Children who died due to severe respiratory and circulatory failure after admission to the ICU; 2) Children with upper digestive tract obstruction who cannot be treated with enteral nutrition through the mouth or feeding tube; 3 ) Children with severe circulatory failure and hepatic and renal insufficiency still existed 48 hours after admission to ICU; 4) During ICU treatment, children with severe digestive tract diseases (such as massive gastrointestinal bleeding, necrotizing enterocolitis, intestinal obstruction, intestinal perforation, etc.), resulting in changes in their condition and unable to continue enteral nutrition support treatment within a short period (1 week); 5) Children who received parenteral nutrition treatment within 1 week after admission to the ICU.

\subsection{Methods}

\subsubsection{Enteral Nutrition Support Program}

At present, according to the nitrogen sources, EN preparations are mainly divided into: essential diet, composed of amino acids; Semi-essential diet, composed of protein hydrolysate (short peptide) composition; Poly diet, composed of whole protein [3]. In addition to special diseases, children with normal ga- 
strointestinal function can choose whole protein preparation. According to the standard of formula food in China, the energy of ordinary formula is 2500 - 2950 $\mathrm{kJ} / \mathrm{L}(600-700 \mathrm{kcal} / \mathrm{L})$ for infants aged 0 - 12 months, and $2500-3550 \mathrm{~kJ} / \mathrm{L}(600$ - $850 \mathrm{kcal} / \mathrm{L}$ ) for infants aged $>12-36$ months. All children were fed with common formula (whole protein, lactose containing formula) at the beginning of feeding, and the feeding method was oral or nasogastric tube feeding, and the specific feeding method could be intermittent or continuous feeding. According to the changes of children's condition and feeding tolerance, gradually increase the amount of feeding, adjust the feeding approach (transition from nasogastric tube feeding to oral feeding), method (transition from continuous feeding to intermittent feeding) and enteral nutrition formula.

\subsubsection{Grouping}

The treatment group, namely the early EN group, was given enteral nutrition treatment within 24 hours after admission to the ICU, and the caloric quantity of enteral nutrition supply reached $25 \%$ or more of the daily normal physiological requirements of the age group. The control group, the late EN group, was given enteral nutrition therapy within 7 days after admission to the ICU, but the caloric quantity of enteral nutrition supply within 24 hours after admission to the ICU was less than $25 \%$ of the normal daily physiological requirements of this age group.

\section{Statistical Analysis}

SPSS 26.0 statistical software package was used for data processing. When the data of measurement were normally distributed, the value was expressed as mean \pm standard deviation $(\chi \pm S)$. T test and Chi-square test were used for statistical analysis of measurement data and count data between groups. For non-normal distribution, two independent sample rank sum tests and two related sample rank sum tests were used for statistical analysis. P $<0.05$ was considered as a statistically significant difference.

\section{Results}

\subsection{Case Characteristics}

A total of 80 patients were included, including 48 males and 32 females. The mean age was $(7.32 \pm 3.19)$ months $(1-64)$ months, and there were no significant differences in gender, age, body weight and infection status at admission to ICU among the two groups ( $\mathrm{P}>0.05$ ) (Table 1$)$. In this study, 45 cases $(93.8 \%)$ in the treatment group were complicated with bacterial infection, while 30 cases $(81.1 \%)$ in the control group, with no statistically significant difference between the two groups $(P>0.05)$. Other treatments including vasoactive drug therapy, diuretic therapy, sedatives and infusion of blood products were not statistically significant between the two groups.

\subsection{Enteral Nutrition}

The average caloric calories in 24 hours of enteral nutrition in the treatment 
group and the control group were $(44.5 \pm 12.5) \mathrm{kcal} \cdot \mathrm{kg}^{-1} \cdot \mathrm{d}^{-1}$ and $(11.4 \pm 9.7)$ $\mathrm{kcal} \cdot \mathrm{kg}^{-1} \cdot \mathrm{d}^{-1}$, respectively, with statistically significant difference between the two groups $(\mathrm{P}<0.05)$. There was no statistically significant difference in feeding approaches, methods and formulations between the two groups, and the rate of feeding intolerance in the treatment group was lower than that in the control group, suggesting that early enteral nutrition can reduce the incidence of feeding intolerance (Table 2).

\subsection{Efficacy Analysis}

1) Comparison of ICU hospitalization days and total hospitalization days between the two groups: the average ICU hospitalization days of the treatment group and the control group were $(6.5 \pm 2.3)$ and $(14.1 \pm 4.4)$ days, respectively, and the average ICU hospitalization days of the treatment group and the control group were $(16.7 \pm 7.4)$ and $(25.4 \pm 3.7)$ days, respectively. Average length of stay in ICU and average length of stay in early enteral nutrition group were shorter than those in control group $(\mathrm{P}<0.05)$ (Table 3$)$.

2) Blood routine and blood biochemistry were compared between the two groups: There was no statistical difference in serum prealbumin between the treatment group and the control group when the two groups were admitted to the ICU ( $t=0.987, P=0.323)$. After one week of treatment, it was found that the white blood cell, neutrophil absolute value (NEUT) and C-reactive protein indexes in the treatment group were lower than those in the control group. There was no statistical significance between the two groups in the entry of serum prealbumin, a nutritional index. After one week of treatment, prealbumin in the

Table 1. General situation of children in the two groups (cases, mean \pm standard deviation).

\begin{tabular}{ccccc}
\hline Group & $\begin{array}{c}\text { Gender } \\
\text { (male/female) }\end{array}$ & Age (month) & Weight (Kg) & $\begin{array}{c}\text { *PCIS } \\
\text { (points) }\end{array}$ \\
\hline Treatment group & $(31 / 17)$ & $5.83 \pm 1.81$ & $6.41 \pm 2.08$ & $86.93 \pm 3.3$ \\
Control group & $(17 / 15)$ & $9.56 \pm 4.32$ & $7.48 \pm 2.93$ & $86.09 \pm 3.8$ \\
$\chi^{2} /$ t value & 1.059 & 2.639 & 2.753 & 1.846 \\
P value & 0.305 & 0.643 & 0.743 & 0.201 \\
\hline
\end{tabular}

Note: ${ }^{\star P C I S}$ : Pediatric critical case score.

Table 2. Enteral nutrition pathways, methods and formulations within 72 hours between the treatment group and the control group (cases).

\begin{tabular}{ccccc}
\hline Group & $\begin{array}{c}\text { Nasal feeding/ } \\
\text { oral feeding }\end{array}$ & $\begin{array}{c}\text { Intermittent feeding/ } \\
\text { continuous feeding }\end{array}$ & $\begin{array}{c}\text { Regular formula/ } \\
\text { special formula }\end{array}$ & $\begin{array}{c}\text { Feeding } \\
\text { intolerance }\end{array}$ \\
\hline Treatment group & $46 / 2$ & $43 / 5$ & $45 / 3$ & 8 \\
Control group & $30 / 2$ & $27 / 5$ & $28 / 4$ & 17 \\
$\chi^{2}$ value & 0.175 & 0.476 & 0.939 & 11.879 \\
P value & 0.675 & 0.490 & 0.332 & $<0.001$ \\
\hline
\end{tabular}


treatment group was higher than that in the control group, and there was no statistically significant difference in albumin between the two groups. After one week of treatment, the white blood cell, NEUT, C-reactive protein and serum prealbumin in the treatment group were all better than before, while serum albumin did not change significantly (Table 4, Table 5).

3) Evaluation of nutritional status of children: The incidence of malnutrition at entry to ICU was $41.7 \%$ in the treatment group and $50 \%$ in the control group, and $35.4 \%$ in the treatment group and $59.4 \%$ in the control group when out of hospital, respectively. It can be seen that there was no significant difference in the incidence of malnutrition between the two groups at the time of entry to ICU,

Table 3. Average length of stay and Total length of stay in ICU (mean \pm standard deviation).

\begin{tabular}{ccc}
\hline Group & $\begin{array}{c}\text { Average length of stay } \\
\text { in intensive care unit (days) }\end{array}$ & $\begin{array}{c}\text { Average Total length } \\
\text { of stay (days) }\end{array}$ \\
\hline Treatment group & $6.5 \pm 2.3$ & $16.7 \pm 7.4$ \\
Control group & $14.1 \pm 4.42$ & $25.4 \pm 3.7$ \\
t value & 56.130 & 3.298 \\
P value & $<0.001$ & 0.013 \\
\hline
\end{tabular}

Table 4. Indicators of children in the two groups after admission to ICU for 1 week (mean \pm standard deviation).

\begin{tabular}{ccccc}
\hline Group & $\begin{array}{c}\text { Treatment } \\
\text { group }\end{array}$ & $\begin{array}{c}\text { Control } \\
\text { group }\end{array}$ & t value & P value \\
\hline WBC $\left(\times 10^{9} / \mathrm{L}\right)$ & $9.4 \pm 2.88$ & $15.6 \pm 5.74$ & 4.736 & 0.003 \\
NEUT $\left(\times 10^{9} / \mathrm{L}\right)$ & $4.5 \pm 1.85$ & $10.7 \pm 4.84$ & 5.649 & $<0.001$ \\
CRP $(\mathrm{mg} / \mathrm{L})$ & $5.1 \pm 4.0$ & $28.2 \pm 5.68$ & 6.073 & $<0.001$ \\
Albumin $(\mathrm{g} / \mathrm{L})$ & $31.9 \pm 3.99$ & $30.8 \pm 3.89$ & 1.815 & 0.536 \\
Serum prealbumin $(\mathrm{mg} / \mathrm{L})$ & $121.2 \pm 29.52$ & $101.0 \pm 31.04$ & 3.476 & 0.017 \\
\hline
\end{tabular}

Note: WBC: White blood cells; NEUT: neutrophils; CRP: C-reactive protein.

Table 5. Indicators of the treatment group at admission to ICU and one week after treatment (mean \pm standard deviation).

\begin{tabular}{ccccc}
\hline Group & $\begin{array}{c}\text { Admitted to } \\
\text { the ICU }\end{array}$ & $\begin{array}{c}\text { 1 week after } \\
\text { treatment }\end{array}$ & t value & P value \\
\hline WBC $\left(\times 10^{9} / \mathrm{L}\right)$ & $12.3 \pm 3.9$ & $9.4 \pm 2.9$ & 4.363 & 0.012 \\
NEUT $\left(\times 10^{9} / \mathrm{L}\right)$ & $9.2 \pm 2.8$ & $4.5 \pm 1.9$ & 5.817 & $<0.001$ \\
CRP $(\mathrm{mg} / \mathrm{L})$ & $25.4 \pm 9.5$ & $5.1 \pm 2.0$ & 5.826 & $<0.001$ \\
Albumin $(\mathrm{g} / \mathrm{L})$ & $30.5 \pm 5.9$ & $31.9 \pm 4.0$. & 1.819 & 0.515 \\
$\begin{array}{c}\text { Serum prealbumin } \\
(\mathrm{mg} / \mathrm{L})\end{array}$ & $107.5 \pm 42.3$ & $121.2 \pm 29.5$ & 3.125 & 0.021 \\
\hline
\end{tabular}

Note: WBC: White blood cells; NEUT: neutrophils; CRP: C-reactive protein. 
Table 6. Comparison of incidence of malnutrition between the treatment group and the control group*.

\begin{tabular}{ccccc}
\hline Group & Treatment group & Control group & $\chi^{2}$ value & P value \\
\hline To the ICU & $20(41.7 \%)$ & $16(50.0 \%)$ & 0.539 & 0.463 \\
Out of the hospital & $17(35.4 \%)$ & $19(59.4 \%)$ & 4.453 & 0.035 \\
\hline
\end{tabular}

Note: ${ }^{\star}$ Malnutrition is defined as moderate to severe malnutrition if the child's weight is below the standard for the age of the same sex.

and the rate of malnutrition in the treatment group when out of hospital was lower than that at the time of entry to ICU, while the rate of malnutrition in the control group was higher, suggesting that early enteral nutrition can improve the incidence of malnutrition in children (Table 6).

\section{Discussion}

Most severe patients are in a state of stress, and the incidence of malnutrition is high. Studies indicate that the prognosis of malnourished children is worse [4], so it is very important to improve the malnutrition of severe children at an early stage. Early feeding can reduce metabolic stress response, prevent oxidative cell damage and regulate immune response, and promote and maintain the integrity and function of gastrointestinal mucosa. Benefits of early EN include fewer infections during ICU dependency, higher cure rates, and an overall improvement in short-term and long-term clinical outcomes. According to the consensus of experts [5], enteral nutrition should be carried out for critically ill children as soon as possible without contraindications, EN support should be started for critically ill patients within 24 - 48 hours after admission to intensive care unit (ICU), and within 24 hours after surgery.

Early enteral nutrition can shorten the length of hospital stay, enhance the ability of children to resist infection, and promote the early improvement of malnutrition. This study showed that the early enteral nutrition group had shorter hospital stay, faster recovery of infection index after one week of treatment, and lower incidence of malnutrition reassessed at discharge. Srinivasan [6] found that early enteral nutrition was independently associated with better clinical prognosis, improving the early and long-term clinical outcomes of children, and children without early enteral nutrition would require parenteral nutrition support earlier. Relevant studies found that [7], compared with early provision of PN (within 24 hours after admission), Critically ill children who did not use complementary parenteral nutrition (PN) during the first week had fewer new infections, less dependence on mechanical ventilation and general intensive care, and shorter hospital stays. In addition, the clinical advantages of late PN in children are more obvious than those in adults, and the advantages are shown regardless of diagnosis, disease severity, risk of malnutrition or age of children [7].

Ma, et al. [8] found that $\mathrm{CD} 3+\mathrm{T}, \mathrm{CD} 4+\mathrm{T}, \mathrm{CD} 8+\mathrm{T}, \mathrm{CD} 4+\mathrm{T} / \mathrm{CD} 8+\mathrm{T}$ cell 
counts and immunoglobulin (Ig) G, IgM and IgA levels in early enteral nutrition group were significantly higher than those in total parenteral nutrition group on the $3^{\text {th }}$ and $7^{\text {th }}$ postoperative days in patients with cholangiocarcinoma. This study found that the early enteral nutrition group after one week of hospitalization, including the percentage of white blood cell, CRP, neutrophil and other indicators were significantly decreased compared with the control group, suggesting that early enteral nutrition can regulate the immune function of children, enhance the immunity of patients, so as to improve the ability of patients to fight infection.

Guidelines indicate [9] the value of early enteral nutrition for infection, combined with the results of seven included multicenter studies (2729 patients), EEN reduced the risk of infection compared with early PN (RR 0.55; 95\% CI 0.35 $\left.0.86 ; \mathrm{P}=0.009 ; \mathrm{I}^{2}=65 \%\right)$. research results of Sahu, et al. [10] showed that carrying out enteral nutrition early after cardiac surgery is feasible, and can help provide adequate nutrition, and reduce ventilation time, infection rate and ICU length of hospital stay in, the total length of hospital stay and mortality, with the results of this study. This suggests patients with early enteral nutrition were beneficial to early rehabilitation and can reduce the incidence rate of children with feeding intolerance.

This article discusses the application of common formula milk powder. Studies have shown that breastfeeding plays an important role in the treatment of premature infants. Because breast milk not only contains rich nutrients, but also contains a large number of biologically active substances, antioxidant substances, growth factors, hormones and human milk oligosaccharides and other important active substances, to prevent diseases, promote the growth of infants and long-term health [11]. In addition, breast milk is rich in living cells, including immune cells and stem cells. Studies have shown that breastfeeding can reduce the incidence of serious diseases in premature infants, promote the early establishment of enteral nutrition in premature infants, and benefit the growth and long-term health of premature infants [12]. The use of breastfeeding in critically ill infants may be further discussed.

\section{Conclusion}

Early enteral nutrition can shorten the length of hospital stay, improve malnutrition as early as possible, improve the anti-infection ability of patients with enhanced immunity, improve the short-term and long-term prognosis of patients, and should be given as early as possible to children without contraindications.

\section{Conflicts of Interest}

The authors declare no conflicts of interest regarding the publication of this paper.

\section{References}

[1] Hulst, J., Joosten, K., Zimmermann, L., Hop, W., van Buuren, S., Büller, H., Tibboel, D. and van Goudoever, J. (2004) Malnutrition in Critically Ill Children: From Ad- 
mission to 6 Months after Discharge. Clinical Nutrition, 23, 223-232.

https://doi.org/10.1016/S0261-5614(03)00130-4

[2] Briassoulis, G., Zavras, N. and Hatzis, T. (2001) Malnutrition, Nutritional Indices, and Early Enteral Feeding in Critically Ill Children. Nutrition, 17, 548-557. https://doi.org/10.1016/S0899-9007(01)00578-0

[3] Yu, Y. and Chen, J. (2017) Exclusive Enteral Nutrition in the Treatment of Pediatric Crohn's Disease. Chinese Journal of Pediatrics, 55, 960-963. (In Chinese) http://doi.org/10.3760/cma.j.issn.0578-1310.2017.12.020

[4] Mehta, N.M., Bechard, L.J., Cahill, N., Wang, M., Day, A., Duggan, C.P. and Heyland, D.K. (2012) Nutritional Practices and Their Relationship to Clinical Outcomes in Critically Ill Children-An International Multicenter Cohort Study*. Critical Care Medicine, 40, 2204-2211. https://doi.org/10.1097/CCM.0b013e31824e18a8

[5] Sun, R., Jiang, R., Huang, M. and Cai, G. (2018) Consensus of Early Enteral Nutrition Clinical Practice in Critically Ill Patients. Chinese Critical Care Medicine, 30, 715-721. (In Chinese)

[6] Vijay, S., Natalie, R.H., Nilesh, M.M., Sharon, Y.I., Sarah, B.K., Hchristine, A., Katri, V.T., Natalie, Z.C., Vincent, S.F., David, W., et al. (2020) Early Enteral Nutrition Is Associated with Improved Clinical Outcomes in Critically Ill Children: A Secondary Analysis of Nutrition Support in the Heart and Lung Failure-Pediatric Insulin Titration Trial. Pediatric Critical Care Medicine, 21, 213-221. https://doi.org/10.1097/PCC.0000000000002135

[7] Bistrian, R.B. (2016) Early Versus Late Parenteral Nutrition in Critically Ill Children. The New England Journal of Medicine, 375, 384-386. https://doi.org/10.1056/NEJMc1605395

[8] Ma, B.Q., Chen, S.Y., Jiang, Z.B., Wu, B., He, Y., Wang, X.X., Li, Y., Gao, P. and Yang, X.J. (2020) Effect of Postoperative Early Enteral Nutrition on Clinical Outcomes and Immune Function of Cholangiocarcinoma Patients with Malignant Obstructive Jaundice. World Journal of Gastroenterology, 26, 7405-7415.

[9] Blaser, A.R., Starkopf, J., Alhazzani, W., Berger, M.M., Casaer, M.P., Deane, A.M., Fruhwald, S., Hiesmayr, M., Ichai, C., Jakob, S., et al. (2017) Early Enteral Nutrition in Critically Ill Patients: Esicm Clinical Practice Guidelines. Intensive Care Medicine, 43, 380-398. https://doi.org/10.1007/s00134-016-4665-0

[10] Sahu, M.K., Singal, A., Menon, R., Singh, S.P., Mohan, A., Manral, M., Singh, D., Devagouru, V., Talwar, S. and Choudhary, S.K. (2016) Early Enteral Nutrition Therapy in Congenital Cardiac Repair Postoperatively: A Randomized, Controlled Pilot Study. Annals of Cardiac Anaesthesia, 19, 653-661. https://doi.org/10.4103/0971-9784.191550

[11] Gila, D.A., Arribas, S.M., Algara, A., Martin, M.A., Lopez, A.L., Saenz, P.M. and Ramiro, C.D. (2019) A Review of Bioactive Factors in Human Breastmilk: A Focus on Prematurity. Nutrients, 11, Article No. 1307.

https://doi.org/10.3390/nu11061307

[12] Victora, C.G., Bahl, R., Barros, A.J., França, G.V., Horton, S., Krasevec, J., Murch, S., Sankar, M.J., Walker, N., Rollins, N.C., et al. (2016) Lancet Breastfeeding Series Group. Breastfeeding in the 21st Century: Epidemiology, Mechanisms, and Lifelong Effect. Lancet, 387, 475-490. https://doi.org/10.1016/S0140-6736(15)01024-7 